\title{
An Unusual Termination of Seven Veins in the Jugulo-Subclavian Junction
}

\author{
Inusual Terminación de Siete Venas en la Unión Yugulo-Subclavia
}

Eleni Panagouli; Athanasios Tsaraklis; Ioanna Gazouli \& Dionyssios Venieratos

PANAGOULI, E.; TSARAKLIS, A.; GAZOULI, I. \& VENIERATOS, D. An unusual termination of seven veins in the jugulosubclavian junction. Int. J. Morphol., 27(4):1257-1260, 2009.

SUMMARY: During anatomical dissection of a female Caucasian cadaver in our department, we observed an unusual termination of seven veins at the jugulo-subclavian junction. Normally, the jugulo-subclavian junction is formed by the union of the internal jugular vein and the subclavian vein, and gives rise to the brachionocephalic vein. In our case, except from these two, five additional veins, namely the cephalic vein, the transverse cervical vein, the external jugular vein, the anterior jugular vein, and the vertebral vein, were also joined at the level of the jugulo-subclavian junction, in order to form the brachionocephalic vein. Such a variation has not yet been reported in the literature.

KEY WORDS: Subclavian vein; Brachiocephalic vein; Cephalic vein; Interior jugular vein; External jugular vein.

\section{INTRODUCTION}

The jugulo-subclavian junction is formed at the base of the neck bilaterally, posterior to the sternal end of the clavicle, by the union of the internal jugular vein (IJV) and the subclavian vein (SCV) (Calen et al., 1986). From this confluence the brachionocephalic vein (BCV) is formed. Then, the left and right $\mathrm{BCV}$ are joined in order to form the superior vena cava. In the present study we report a case in which at the level of the jugulo-subclavian junction, seven veins instead of two are joined in order to form the brachionocephalic vein.

\section{MATERIALS AND METHOD}

The reported anatomical variations were discovered in the right side of a female Caucasian cadaver (deceased at the age of 89 from respiratory insufficiency), during routine educational dissection at the Anatomy Department of the Medical School of the University of Athens, Greece.

\section{RESULTS}

On the right upper arm and posterior to the sternal end of the clavicle we discovered that seven veins were united in order to form the right BCV vein (Fig. 1). Dissecting the area from the acromial end of the clavicle to the base of the neck (supraclavical triangle), we noticed that four veins joined the SCV in the following order (clockwise, seen from the front): the cephalic vein (CV), the transverse cervical vein (TCV), the external jugular vein (EJV) and the anterior jugular vein (AJV) (Fig. 2). The next vein to join the junction was the internal jugular vein (IJV), following its expected course. The last vein to reach the common junction was the vertebral vein (VV) (also clockwise). It should be pointed out, that the $\mathrm{CV}$, after piercing the clavipectoral fascia, did not join the axillary vein as usual, but instead, crossed over the clavicle and ended at the common junction. Also, the AJV was rather thick and was larger than the EJV and the IJV. Accordingly, the right BCV vein was formed after the junction from all these veins. Its length was $5.8 \mathrm{~cm}$ and after its formation, continued its course as expected. The course of the other seven veins was also normal (except CV) until the point of the junction. 


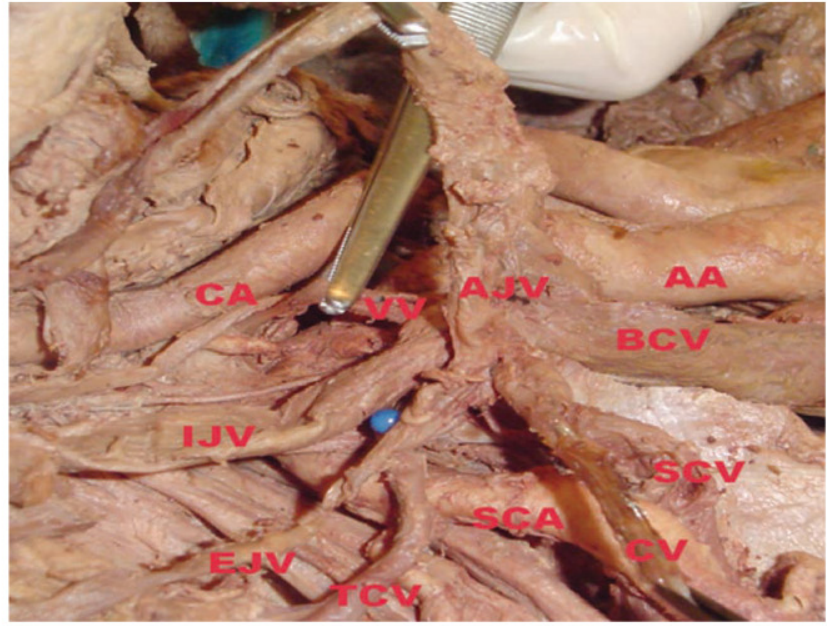

Fig. 1. Common junction of seven veins. SCV. Subclavian vein; CV. Cephalic vein; TCV; Transverse cervical vein; EJV. External jugular vein; AJV. Anterior jugular vein; IJV. Internal jugular vein; VV. Vertebral vein; CA. Carotid artery; SCA. Subclavian artery; AA. Anonymous artery; BCV. Brachionocephalic vein. The clavicle has been pulled out.

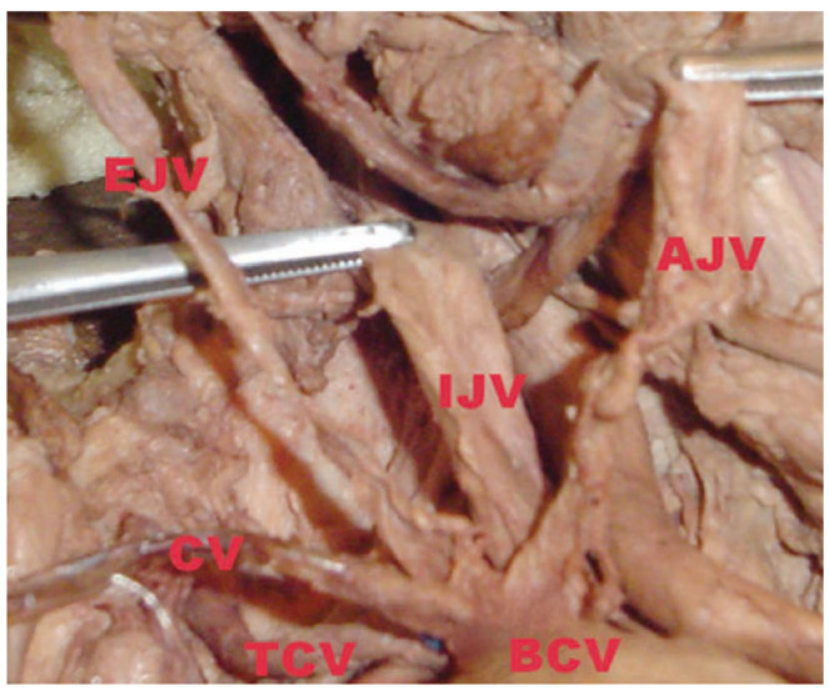

Fig. 3. Common junction from the front. CV. Cephalic vein; TCV. Transverse cervical vein; EJV. External jugular vein; AJV. Anterior jugular vein; IJV. Internal jugular vein; BCVBrachionocephalic vein.

\section{DISCUSSION}

The normal termination of the veins involved in our description (found in classical anatomic textbooks), as well as their most frequently reported variations are as follows:

The SCV is the continuation of the axillary vein. It starts at the outer border of the first rib and ends at the jugulosubclavian junction. The IJV courses with the carotid artery

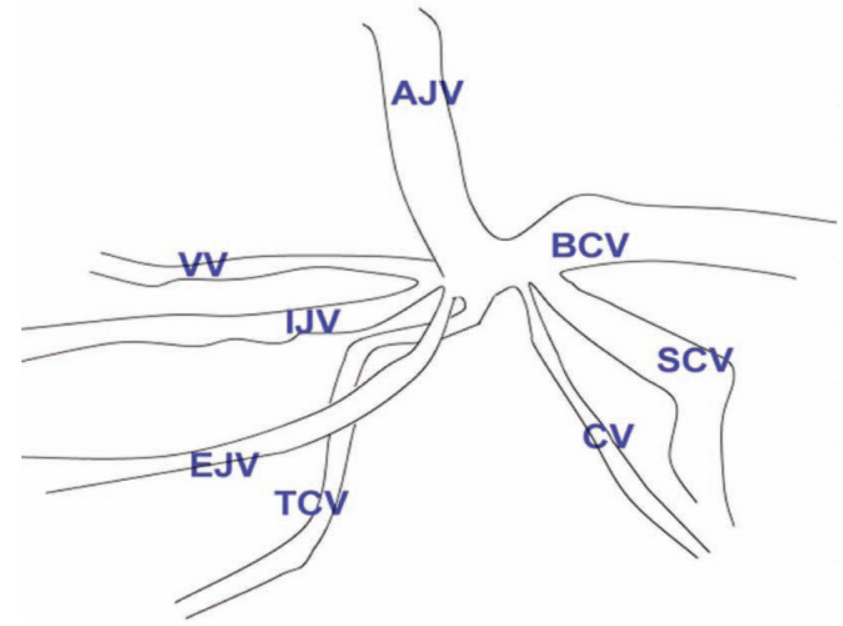

Fig. 2. Common junction of seven veins. Schematic representation. SCV. Subclavian vein; CV. Cephalic vein; TCV. Transverse cervical vein; EJV. External jugular vein; AJV. Anterior jugular vein; IJV. Internal jugular vein; VV. Vertebral vein; BCV. brachionocephalic vein.

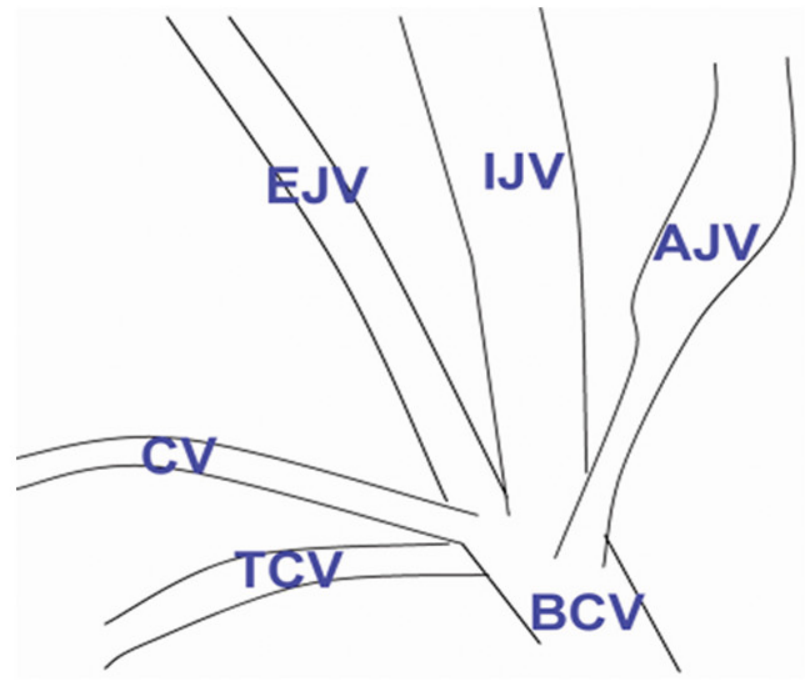

Fig. 4. Schematic representation. CV. Cephalic vein; TCV. Transverse cervical vein; EJV. External jugular vein; AJV. Anterior jugular vein; IJV. Internal jugular vein; BCV. Brachionocephalic vein.

and the pneumonogastric nerve in the carotid sheath and normally reaches the jugulo-subclavian junction.

The EJV normally runs superficial to the sternocleidomastoid muscle at the root of the neck where it ends in the SCV, after crossing the deep fascia. It is larger than the other veins at the region of the neck and sometimes 
has even the double diameter (Standring et al., 2008). The EJV has been found to flow in the jugulo-subclavian junction in the anatomical study of Deslaugiers et al. (1994) on 50 cadavers in $60 \%$, either directly in $8 \%$ or after having formed a common trunk, most often formed on the right, with the $\mathrm{TCV}$ in 52\%. The termination of the EJV in the jugulosubclavian junction has also been noted by Sobbota as well as by Bouchet \& Guilleret (Deslaugiers et al.). The EJV has also been found to drain into the IJV in $4 \%$ by Deslaugiers et al. and in one third of the cases by Hollinshead (1954).

The TCV usually ends in the EJV. According to Deslaugiers et al. the TCV flows in the EJV in $88 \%$ or in the jugulo-subclavian junction in $4 \%$. A case where the TCV and the EJV terminated separately in the IJV has also been described (Prakash et al., 2006).

The AJV descends between the midline and the anterior border of the sternocleidomastoid muscle and ends in either the EJV or the SCV (Testut \& Latarjet, 1948). The AJV opens into the EJV (as reported by Deslaugiers et al., 1994 ) in $46 \%$ and into the SCV in $54 \%$ of the cases. Its diameter is usually inverse to that of the EJV (Standring et $a l$.). It might be larger than the EJV in case of thrombosis of the EJV (Nayak, 2006; Schummer et al., 2004). In one case cited by Fabian \& Gesase (2006) the right AJV opened into the jugulo-subclavian venous confluence while the left AJV drained into the left IJV just before the formation of the confluence. Moreover, a case of the AJV joining the common facial vein in combination with the termination of the EJV in the IJV has been also described (Prakash et al.).

The CV most commonly joins the axillary vein just below the clavicular level. Nevertheless, its termination has been found in the EJV (Au, 1989; Ishizuka, 1964); directly or indirectly into the basilic vein (Bergman et al., 2008; Saaid
\& Drysdale, 2008); and into the SCV (Ishizuka). In one case it has been found to drain into the IJV just above the confluence of the latter with the SCV (Saaid \& Drysdale). In the study of Deslaugier et al., the CV in $2 \%$ of the cases formed the EJV, after crossing over the clavicle. The CV is thin or absent in 20\% (Le Saout et al., 1983).

Finally, the VV usually ends in the BCV. In the literature accessible to us, there have been no variations of its termination reported.

In our case the SCV, the CV, the TCV, the EJV, the AJV, the IJV and the VV ended all in the same junction at the level of the jugulo-subclavian junction or confluence of Pirogoff and formed the BCV. As far as we know there no other reports yet in the literature of such a variation.

The knowledge of such anatomical variation is clinically important for surgeries in the head and neck area and for catheterizations (Le Saout $e t a l$.). A very common procedure is the cannulation of a central vein in the neck, such as the IJV, the EJV and the SCV (Asouhidou et al., 2008; Schummer et al.). Particularly, the IJV seems to be the vein that is most used for central venous access and especially the right one, because of the absence of the thoracic duct (Asouhidou et al.; Dennis \& Uretsky 1991). The AJV may be an alternative route for central venous catheterization, but also might cause malposition of the catheter (Schummer et al.). Additionally, the CV is commonly used for endocardial lead implantation of a pacemaker or a cardioverter-defibrillator (Le Saout et al.; Furman, 1986). The presence of a variation like the one we describe, might cause complications of problems during the procedures described above (noticeably, the dissected woman had a peacemaker normally implanted as usual through its cephalic vein).

PANAGOUli, E.; TSARAKLIS, A.; GAZOULI, I. \& VENIERATOS, D. Inusual terminación de siete venas en la union yugulosubclavia. Int. J. Morphol., 27(4):1249-1256, 2009.

RESUMEN: Durante la disección anatómica de un cadáver caucásico femenino, se observó una inusual terminación de siete venas en el lugar de unión yúgulo-subclavia. Normalmente, la unión yúgulo-subclavia consiste en la unión de la vena yugular interna y la vena subclavia, que forman la vena braquiocefálica. En nuestro caso, además de estas dos venas, se observaron cinco venas adicionales, la vena cefálica, la vena cervical transversa, la vena yugular externa, la vena yugular anterior y la vena vertebral, la que también se unió en el nivel de la unión yúgulo-subclavia, a fin de formar la vena braquiocefálica. Tal variación no ha sido reportado en la literatura.

PALABRAS CLAVE: Vena subclavia; Vena braquiocefálica; Vena cefálica; Vena yugular interna; Vena yugular externa.

\section{REFERENCES}

Asouhidou, I.; Natsis, K.; Asteri, T.; Sountoulides, P.; Vlasis, K. \& Tsikaras, P. Anatomical variation of the left internal Jugular vein:clinical significance for an anaesthesiologist. Eur. J. Anaesthesiol., 25(4):314-8, 2008. 
Au, F. C. The anatomy of the cephalic vein. Am. Surg., 55(10):638-9,1989.

Bergman, R. A.; Afifi, A. K. \& Miyauchi, R. Upper limb. Illustrated Encyclopediaof Human Anatomic Variation: Opus II: Cardiovascu lar System: Veins. Avalaible in: http://:www.anatomyatlases.Org, 2008.

Calen, S.; Pommereau, X.; Gbikpi-Benissan, A. M. \& Videau, J. Morphologic and functional anatomy of the subclavian. Surg. Radiol. Anat., 8(2):121-9, 1986.

Denys, B. G. \& Uretsky, B. F. Anatomical variations of internal jugular vein location: impact on central venous access. Crit. Care Med., 19(12):1516-9, 1991.

Deslaugiers, B.; Vaysse, P.; Combes, J. M.; Guitard, J.; Moscovici, J.; Visentin, M.; Vardon, D. \& Bécue, J. Contribution to the study of the tributaries and the termination of the external jugular vein. Surg. Radiol. Anat., 16(2):173-7,1994.

Fabian, F. M. \& Gesase, A. P. Anomalous jugular veins system in an adult male cadaver. Ital. J. Anat. Embryol., 111(4):215-20, 2006.

Furman, S. Venous cutdown for pacemaker implantation. Ann. Thorac. Surg., 41(4):438-9, 1986.

Hollinshead, W. H. Anatomy for surgeons. Head and Neck. New York, Hoeber Harper Book, 1954. V. 1.

Ishizuka, H. Über die variationen der mündungsweise der V. cephalica. Yokohama Med. Bull., 15:79-89, 1964.

Le Saout, J.; Vallee, B.; Person, H.; Doutriaux, M.; Blanc, J. \& Nguyen, H. Anatomical basis for the surgical use of the cephalic vein (V. Cephalica). 74 anatomical dissections. 189 surgical dissections. J. Chir., 120(2):131-4, 1983.

Nayak, B. S. Surgically Important Variations of the Jugular Veins. Clin. Anat., 19(6):544-6, 2006.

Prakash, R.; Prabhu, L. V.; Kumar, J.; Nayak, V. \& Singh, G. Variations of jugular veins: phylogenic correlation and clinical implications. South. Med. J., 99(10):11467, 2006.

Saaid, A \& Drysdale, I. Unusual termination of the cephalic vein. Clin. Anat., 21(8):786-7, 2008.

Schummer, W.; Schummer, C.; Bredle, D. \& Frober, R. The anterior jugular venous system: variability and clinical impact. Anesth. Analg., 99(6):1625-9, 2004.

Standring, S.; Borley, N. R.; Collins, P.; Crossman, A. R.; Gatzoulis, M. A.; Healy, J. C.; Johnson, D.; Mahadevan, V.; Newell, R. L. M. \& Wigley, C. B. Gray's anatomy. The anatomical basis of clinical practice. Edinburgh, Elsevier, 2008.

Testut, L \& Latarjet, A. Traité d'Anatomie Humaine. Paris, G. Doin \& Cie, 1948. Tome 2.

\section{Correspondence to:}

Dionyssios Venieratos, Department of Anatomy

Medical School, University of Athens

Mikras Asias Str. 75, 11627

Athens, GREECE

Tel: 302107462394

Fax: 302107462398

Email: dvenieratos@med.uoa.gr

Received:

Accepted: 